\title{
analysis
}

\section{Fighting malaria at the crossroads}

Thetools to battlethe disease exist, but the lack of political will in developed nationsjeopardizes their success

E ery year, malaria kills between 1 and 3 million people-mostly children under five years of age and pregnant women-and newly infects 300 million to 500 million. But malaria is by no means a problem for developed countries, where it was defeated a long time ago. This is the main obstacle to the fight against the disease: as measures to curb malaria are predominantly financed by rich countries who are not affected by the disease, there is little incentive for them to provide sufficient attention and money towards finding effective solutions for treatment and prevention. In the meantime, the situation in poor countries is alarming, particularly in Africa where $90 \%$ of the global deaths and infections occur. N ot only does malaria seize young lives, but it also cripples the economies of afflicted nations. The World Health Organization (WHO) estimates that malaria costs some $1.3 \%$ of the annual gross domestic product of the states in which the disease flourishes; their economies have been cut by more than $30 \%$ since 1960 as a result of decreases in fertility, population growth, saving and investment, and worker productivity, coupled with increases in absenteeism, premature mortality and medical costs. In some parts of Africa, families spend as much as $25 \%$ of their income on malaria treatments. Even worse, the burden of malaria continues to increase due to widespread parasite resistance to existing drugs, the geographic expansion of insecticide-resistant Anopheles mosquitoes

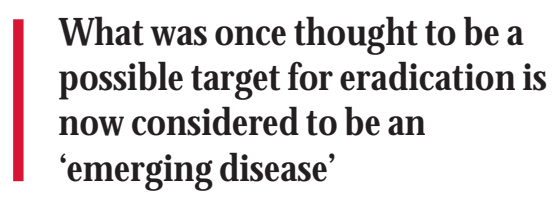

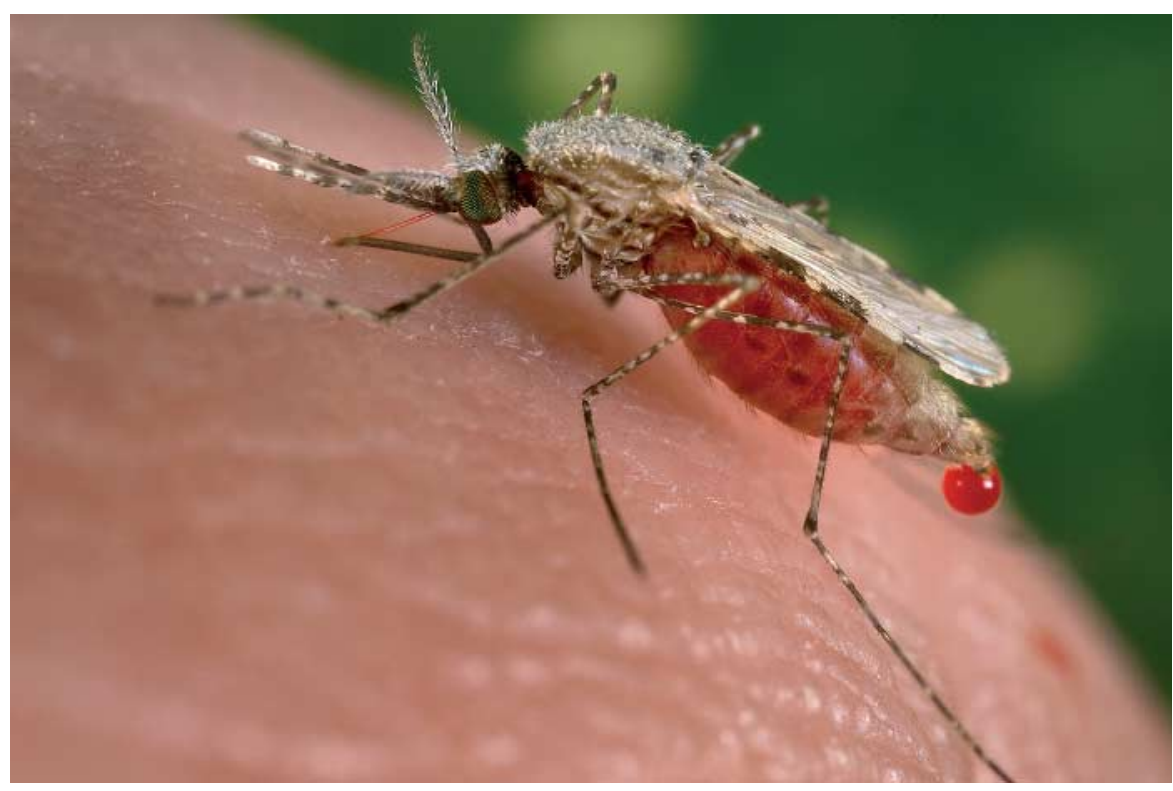

Fig1|An Anopheles stephensi mosquito, a known malaria vector, feeding. @ Centersfor Disease Control and Prevention, Atlanta, GA, USA/Dr William Collins

(Fig 1) and a chronic infrastructural and organizational inability to tackle the problem. The Africa Malaria Report 2003 stated that in some parts of Africa the number of children killed by malaria doubled between the 1980s and 1990s (WHO \& UNICEF, 2003). Thus, what was once thought to be a possible target for eradication is now considered to be an 'emerging disease'.

$\mathrm{N}$ evertheless, the blight finally seems back on the political agenda of developed nations and international institutions. Roll Back Malaria (RBM; www.rbm.who.int), a global partnership that includes the WHO and the United Nations, was launched in 1998 , and endorsed two years later by African heads of state in Abuja, Nigeria, with a commitment to halve the number of deaths from malaria worldwide by 2010 . The Geneva-based Global Fund to Fight AIDS, Tuberculosis and Malariafinanced by developed nations-now provides resources for a variety of malaria programmes, and even private donors are becoming aware of the problem: the Bill \& Melinda Gates Foundation awarded US\$168 million-to be used as grants for malaria initiatives- the biggest ever single donation for the disease. On the research front, the genomes of both the insect vector Anopheles gambiae and the parasite Plasmodium falciparum have been sequenced ( $\mathrm{Holt}$ et al, 2002; Gardner et al, 2002), which will lead to a better understanding of host-parasite and vector-human interactions at the molecular level. At the same time, progress has 
been made over the past decade on other aspects of the disease, from drugs (Fidock et al, 2004; www.mmv.org) to vaccines (W ebster $\&$ Hill, 2003; www.malariavaccine.org), and from transgenic approaches for mosquito control (Nirmala \& James, 2003) to the development of new insecticides (Borovsky, 2003).

Research on the vector and parasite genomes suggests that blocking transmission in the mosquito could become an effective way to stop the disease. Fotis Kafatos's research group at the European Molecular Biology Laboratory (EMBL) in $\mathrm{H}$ eidelberg, Germany, has recently identified three mosquito genes that control the insect's immune response to Plasmodium (O sta et al, 2004). They showed that two insect C-type lectin (CTL) proteins protect the parasite from the Anopheles innate immune system as it develops in the mosquito gut, whereas a third leucine-rich repeat immune (LRIM) protein has the opposite effect. Selective gene silencing of CTLs resulted in the death of invading parasites in massive numbers, whereas inactivation of the LRIM gene led to a substantial increase in Plasmodium numbers. Thus, modulation of these proteins could expose the parasite to the mosquito's immune system, offering real options for fighting the disease in the insect before it is passed to humans, according to Kafatos. Another EMBL team led by Elena Levashina demonstrated that a mosquito glycoprotein, TEP1, binds to and mediates the killing of midgut stages of the parasite (Blandin et al, 2004). Taken together, TEP1 and LRIM studies show that it may be possible to block the parasite-mosquito cycle by enhancing the mosquito immune system, according to the TEP1 article's lead author Stephanie Blandin.

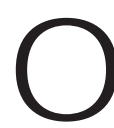

$\mathrm{n}$ another front, the quest for a malaria vaccine is still being actively pursued, although an effective jab has remained elusive for decades. O ne proponent of this approach, Stephen Hoffman, previously at Celera Genomics where he worked on sequencing the A. gambiae genome, has founded a company named Sanaria (Rockville, $M D, U S A)$ to "develop and commercialize a safe and effective malaria vaccine in seven years," and is obtaining funds from public and private sources. In fact, new results from his research are raising hopes. Based on the classic idea of using irradiated sporozoites- the parasite stage that infects the liver-Hoffman showed that up to $90 \%$ of human recipients were protected following bites from more than 1,000 irradiated, infected mosquitoes (Hoffman et al, 2002). His plan is to obtain attenuated sporozoites from infected and irradiated mosquitoes bred by the millions in the lab, and use them directly as a vaccine.

\section{... it may be possible to block the parasite- mosquito cycle by enhancing the mosquito immune system...}

However, Margaret Mackinnon and Andrew Read at the University of Edinburgh, UK, have recently shown that vaccines against malaria could cause the parasite to evolve into an even more deadly form (Mackinnon \& Read, 2004). Performing an experimental evolution of the rodent malaria parasite, Plasmodium chabaudi, in immunized and naive mice, they found that parasites that evolved in immunized mice were more virulent than parasites that evolved in naive mice. If host immunity does indeed increase virulence in malaria pathogens, they fear all efforts devoted to vaccine development might be crippled. Read cautioned that vaccines should not be hailed as a magic bullet, and stressed that his and Mackinnon's observations reinforce the need to explore alternative strategies to eliminate malaria (Pearson, 2004).

"Antimalaria strategies must seek irreversible end-points, goals that will permit intervention coverage to be reduced. This is particularly critical in the case of malaria because immunity is 'diseasemodifying' rather than 'sterilizing'," said Andrew Spielman from the School of Public Health and Center for International Development at Harvard University (Boston, MA, USA). "Where malaria is highly endemic, everyone is infected and relatively few residents are symptomatic. A transiently successful intervention, therefore, would eventually increase everyone's vulnerability to this disease. This implies that we should not expect too much from the use of drugs or insecticides because of resistance, and from vaccines," Spielman cautioned. "Fundamental improvement in the malaria situation probably will

depend upon environmental management and home improvement." Mackinnon believes a better deployment of existing devices, which block transmission at the vector level and reduce the length of time that people are infectious to mosquitoes, should be attempted. "In the meantime, we should be examining the impact of any potential control measure on transmission, and on the parasite's evolutionary response to it," she said.

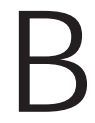
ut although effective strategies exist, they are not used owing to a lack of political will. The outcry over this dismal situation was launched in the pages of the Lancet by Amir Attaran and colleagues of the Royal Institute of International Affairs in London (Attaran et al, 2004). "W ith nearly half the time to the 2010 deadline now past, progress on effective treatment is so inadequate that Roll Back Malaria is failing to reach its targets," they wrote. The main reason behind the increase in malaria deaths, they continued, is drug resistance in P. falciparum caused by the continuing use of outdated drugs, such as chloroquine and sulphadoxine-pyrimethamine, which are largely ineffective in most parts of Africa. This leaves only one possibility: artemisinin. This natural compound and its derivatives have proved to be very effective in treating different forms of the disease, killing parasites resistant to other drugs and avoiding the development of resistance in P. falciparum. A metaanalysis demonstrated the efficacy of artemisinin-class combination therapies (ACTs) by showing that $90 \%$ of patients could be successfully treated in just three days by adding artemisinin compounds to standard drug regimens (International Artemisinin Study Group, 2004). Another combination of an artemisinin with the recently released antimalarial chlorproguanildapsone (Lapdap) is now being investigated (Alloueche et al, 2004).

However, it is scandalous, accuse Attaran and his co-authors in the Lancet article, that although the WHO openly admits the failure of old drugs and recommends ACT as the therapy of choice in areas where malaria ravages, the organization and the Global Fund continue to finance African countries for the purchase of only chloroquine and/or sulphadoxinepyrimethamine, while actively discouraging them from switching to artemisinins. The 


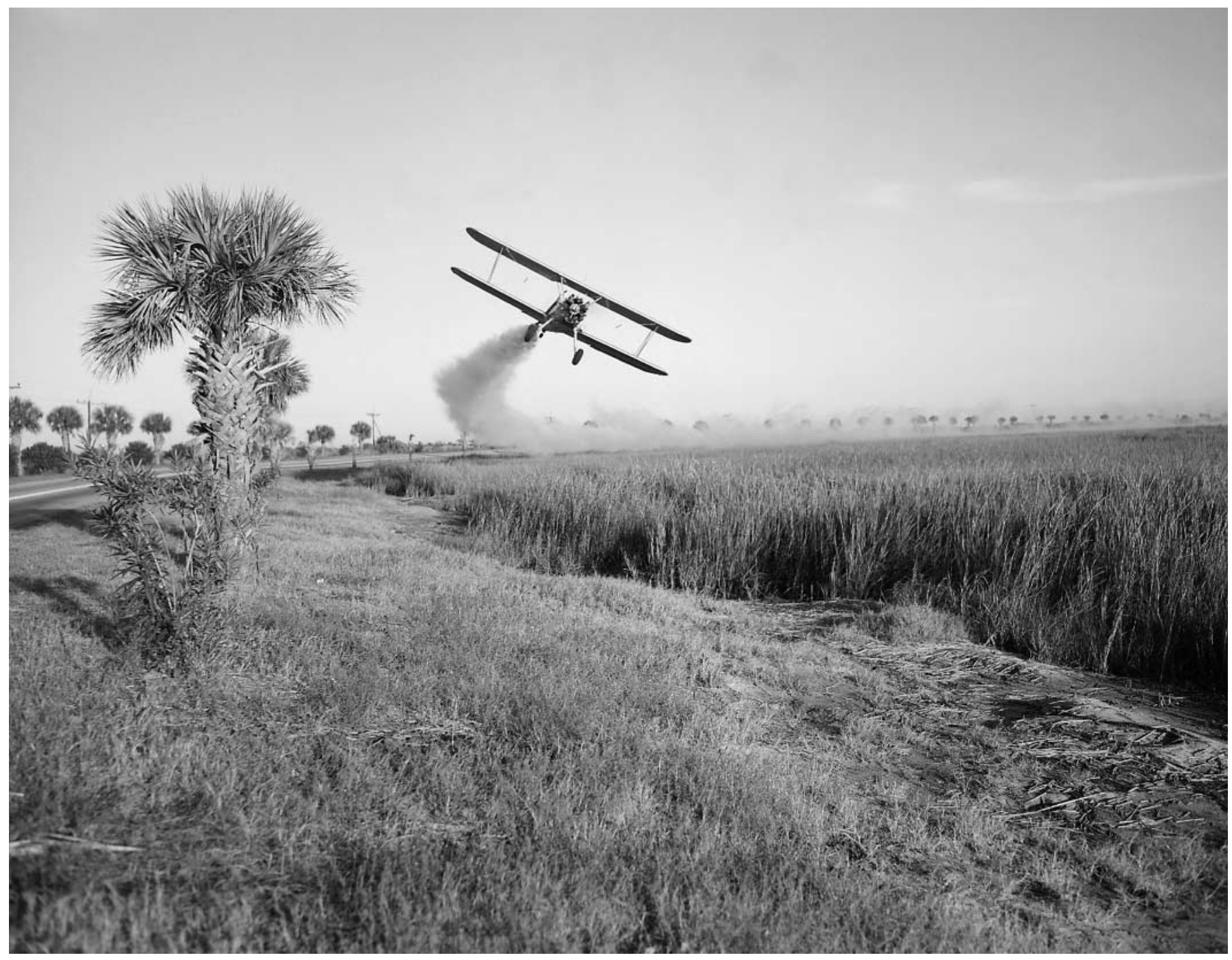

Fig2 |A Stearman bi-plane spraying an insecticide during malaria control operations in Savannah, GA, USA. @ Centers for DiseaseControl and Prevention, Atlanta, GA, USA. Year unknown.

reason is the significant unit price difference between chloroquine (US\$0.13), sulphadoxine-pyrimethamine (US\$0.14) and ACT (US\$1.00-3.00). Instead of signing the new cheque, major supporters of the WHO and Global Fund, such as the USA and UK, have pressured grantreceiving governments to avoid artemisinins (Butler, 2004).

Another critical strategy is the use of insecticide-impregnated bed nets, which are so effective in preventing infection and reducing childhood mortality from malaria that RBM has made it one of its key strategies, aiming to put $60 \%$ of those who need it under a treated net by 2005 . But with little time remaining, only $2 \%$ of children sleep under these nets at present, signalling that current schemes for the distribution of nets to poor communities are not appropriate for achieving the targets agreed on in Abuja. A novel 'proactive pro-poor strategy' was proposed to link bed-net distribution to other existing disease-control programmes, which would reduce operational costs and at the same time offer additional health benefits (M olyneux \& N antulya, 2004).

$\Lambda$ $\mathrm{n}$ even more controversial issue is the use of dichloro-diphenyltrichloroethane-commonly known as DDT-to control infected mosquitoes. DDT has a long history in Europe and N orth A merica (Figs 2, 3); it was widely used in agriculture as a pesticide and was instrumental in wiping out malaria in these continents and in large parts of Asia and Latin America. N ow, several African countries are seriously reconsidering the use of DDT to control malaria in their most afflicted territories. What makes DDT so attractive is that it is much cheaper than the commonly used pyrethroid insecticides and it is very effective. M oreover, mosquito resistance to DDT has not yet been reported, whereas it is rapidly spreading for pyrethroids. But the problem with DDTnow banned almost worldwide-rests with its persistence in the ecosystem, where it accumulates along food chains and causes widespread environmental damage.

Building on past experience, this time DDT will be used more wisely, and only 


\section{science $\&$ society}

in small quantities for spraying homes to kill mosquitoes that rest on the walls and bite at night. This method has proved to be both remarkably safe for people-as it probably is for the environment-and effective in controlling the spread of infection. South Africa is leading the small patrol of nations that use DDT for routine malaria control, and the results speak for themselves. Malaria cases soared in the KwaZulu Natal province of South Africa after it stopped using DDT in 1996, and its reintroduction in 2000 brought the disease back under control. That is enough for other countries, such as $U$ ganda and Kenya, to examine whether DDT could also work for them. The $U$ gandan Minister of Health, Jim Muhwezi, recently defended the plan to use DDT for indoor spraying in his country, emphasizing the need for a proactive rather than reactive strategy against malaria (Wendo, 2004).

\section{"DDT is a victim of its success, having so thoroughly eliminated malaria in wealthy nations that we forget why we once needed it."}

So why then is DDT not the weapon of choice to eradicate malaria? The answer is: simply because of its bad reputation in the USA and Europe. For this reason, major donors, such as the Global Fund and the US Agency for International Development, do not finance its use and the WHO dissuades poor countries from adopting it. This does not make any sense to some critics; for example Tina Rosenberg from the $\mathrm{New}$ York Times argues that environmental concerns about DDT in wealthy nations cripple African populations suffering from malaria (Rosenberg, 2004). "Given the malignant history of American companies employing dangerous drugs and pesticides overseas that they would not or could not use at home, it is understandable why Washington officials say it would be hypocritical to finance DDT in poor nations," Rosenberg wrote in her harshly critical article. "But children sick with malaria might perceive a more deadly hypocrisy in our failure to do so: America and Europe used DDT irresponsibly to wipe

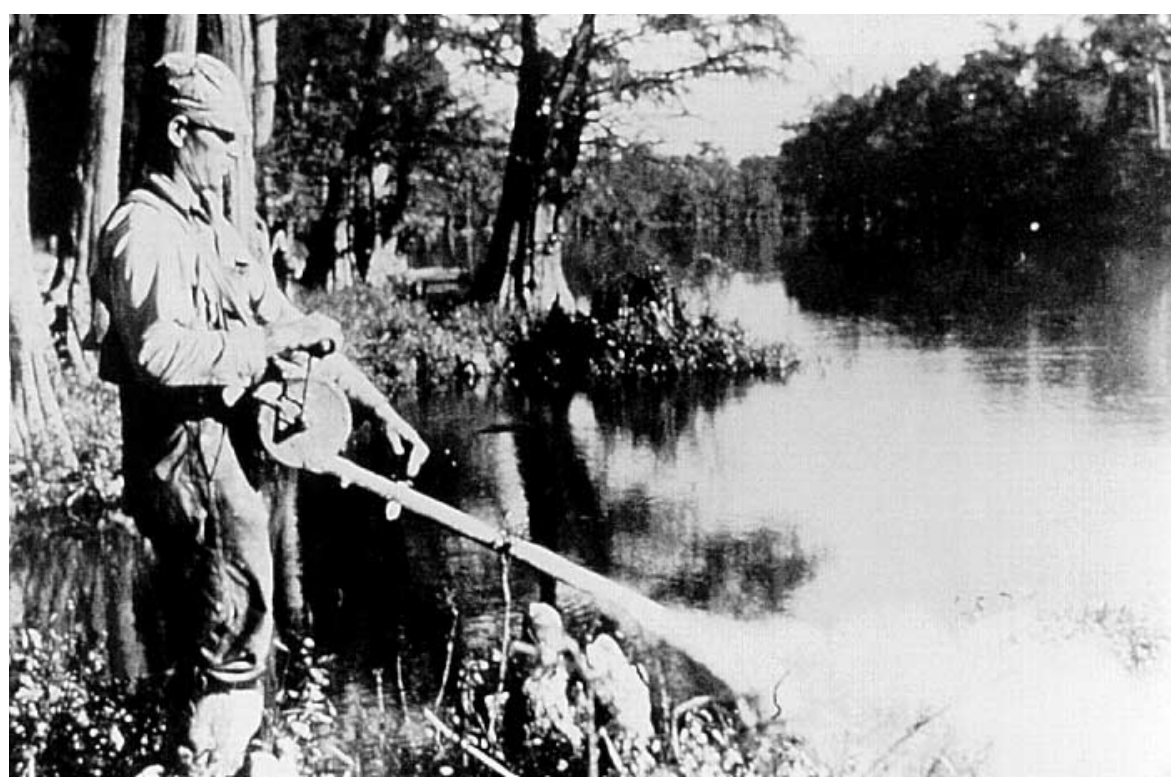

Fig3 The National M alaria Eradication Program in the USA, starting in 1947, used DDT spraying to control mosquitoes. @ Centers for Disease Control and Prevention, Atlanta, GA, USA. Year unknown.

out malaria. Once we discovered it was harming the ecosystem, we made even its safe use impossible for far poorer and sicker nations." The moral of this story, remarked Rosenberg, is that "DDT is a victim of its success, having so thoroughly eliminated malaria in wealthy nations that we forget why we once needed it."

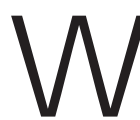
hat is at risk is antimalarial action on a global scale. "The question now is whether the campaign can be saved," commented Gavin Yamey, assistant editor of BMJ Learning, on the looming failure of the RBM initiative (Yamey, 2004). "We have the three tools we need to curb malaria deaths: bed nets, effective combination treatment based on artemisinin, and insecticides. What we urgently need to do is make these tools much more widely available to affected communities, which are almost always too poor to pay for them themselves." Comparing it to AIDS activism that has brought affordable HIV therapy to some of the world's poorest countries, he argued for a similar 'malaria activism' to increase funding. Activism apparently has started: the Global Fund has decided to revise all malaria grants awarded to African countries to specify only artemisinin-based therapies and to

\section{"We have the threetools we need to curb malaria deaths: bed nets, effective combination treatment based on artemisinin, and insecticides. What we urgently need to do is make these tools much more widely available to affected communities..."}

stipulate their use in future funding (Butler, 2004). Furthermore, the agency is planning to finance some DDT spraying in Somalia (Rosenberg, 2004).

$\mathrm{O} n$ the basis of current research, 'hightech' molecular approaches to fight malaria will probably be possible within 10-20 years. These will be based on vaccines, mosquitoes genetically modified to be resistant to parasitic infection and transmission, and new antimalarial drugs and insecticides. In the meantime, low-tech solutions are available that-if applied effectively-might save Africa from its tragic destiny. We are at the crossroads. While researchers follow the path towards scientific advances for malaria control, the path leading to the political and financial implementation of existing effective measures is still in the shadows. 


\section{REFERENCES}

Alloueche A et al (2004) A double-blind randomised comparison of chlorproguanildapsone with sulfadoxine-pyrimethamine for the treatment of uncomplicated falciparum malaria in young African children. Lancet $\mathbf{3 6 3}$ : 1843-1848

Attaran A et al (2004) WHO, the Global Fund, and medical malpractice in malaria treatment. Lancet 363: 237-240

Blandin S, Shiao S-H, M oita LF, Janse CJ, Waters AP, Kafatos FC, Levashina EA (2004) Complementlike protein TEP1 is a determinant of vectorial capacity in the malaria vector Anopheles gambiae. Cell 116: 661-670

Borovsky D (2003)Trypsin-modulating oostatic factor: a potential new larvicide for mosquito control. J Exp Biol 206: 3869-3875

Butler D (2004) G lobal fund changes tack on malaria therapy. N ature 429: 588

Fidock DA, Rosenthal PJ, Croft SL, Brun L, N waka S (2004) Antimalarial drug discovery: efficacy models for compound screening. $\mathrm{N}$ at Rev Drug Discov 3: 509-520

Gardner MJ et al (2002) Genome sequence of the human malaria parasite Plasmodium falciparum. N ature 419: 498-511

Hoffman SL et al (2002) Protection of humans against malaria by immunization with radiation attenuated Plasmodium falciparum sporozoites. J Infect D is 185: 1155-1164

Holt RA et al (2002) The genome sequence of the malaria mosquito Anopheles gambiae. Science 298: $129-149$

International Artemisinin Study G roup (2004)

Artesunate combinations for treatment of malaria: meta-analysis. Lancet 363: 9-17

Mackinnon MJ, Read AF (2004) Immunity promotes virulence evolution in a malaria model. PLOS Biology 2:

doi: 10.1371/journal.pbio.0020230

Molyneux DH, N antulya VM (2004) Linking disease control programmes in rural Africa: a pro-poor strategy to reach Abuja targets and millennium development goals. BMJ 328: 1129-1132

Nirmala X, James AA (2003) Engineering Plasmodium-refractory phenotypes in mosquitoes. Trends Parasitol 19: 384-387

O sta M A, Christophides GK, Kafatos FC (2004) Effects of mosquito genes on Plasmodium development. Science 303: 2030-2032

Pearson H (2004)Vaccines may increase virulence. $N$ ature Publishing G roup News@nature, 22 June. doi: 10.1038/news040621-3

Rosenberg T (2004) What the world needs now is DDT. New York Times, 11 April

Webster D, H ill AVS (2003) Progress with new malaria vaccines. Bull World H ealth 0 rgan 81: 902-909

Wendo C (2004) U ganda considers DDT to protect homes from malaria. Lancet 363: 1376

WHO, UN ICEF (2003) The Africa M alaria Report 2003. WHO/CDS/M AL/2003.1093. World Health O rganization, Geneva, Switzerland

Yamey G (2004) Roll Back M alaria: a failing global health campaign. BMJ 328: 1086-1087

\section{Andrea Rinaldi}

doi:10.1038/sj.embor.7400244

\section{Room of its own}

\author{
Thenew Janelia Farm Research Campus for multidisciplinary research \\ is a major change in strategy for theH oward Hughes M edical Institute
}

$\mathrm{T}$ his autumn, the Howard Hughes Medical Institute (HHMI; Chevy Chase, MD, USA) will begin an initial recruiting round for scientists to conduct research at its new campus, Janelia Farm, which it is now building in rural Loudoun County, Virginia, about a 45-minute drive from Washington, DC. The U $\$ 500$ million project broke ground in May 2003 and will house 200-300 permanent scientific staff on 281 acres when operational in the summer of 2006. It represents a radical change from HHMl's current model of funding researchers at home institutions, towards creating a multidisciplinary and collaborative research environment that incorporates various aspects of other independent research institutions around the world.

"In our vision of building a new model of research community, we have created nothing original, but rather have made use of many aspects of various models worldwide, including the Medical Research Council [MRC] Laboratory of Molecular Biology [LMB] in Cambridge, UK, the European Molecular Biology Laboratory [EMBL; Heidelberg, Germany], and Bell Labs in Murray Hill [NJ, USA]," said geneticist Gerald Rubin, Vice President of $\mathrm{HHMI}$ and Director of the Janelia Farm Research Campus (Fig 1). W hile they all differ radically from each other, these successful research environments share certain characteristics: they have small, individual research groups with leaders who are active bench scientists; internal, dependable and generous funding; excellent support facilities and infrastructure; high staff turnover with limited or no tenure, and an emphasis on originality, creativity and collegiality. 0 ther institutions that served as a model for the Janelia Farm plan were Cold Spring Harbor Laboratories (Cold Spring Harbor, NY, USA) and the Carnegie Institution of Washington's Department of Embryology (Baltimore, MD, USA).

"The plan for Janelia Farm corresponds to a European model of research, but goes beyond what European institutions fund," commented Daniela Rhodes, a structural biologist who works on chromatin and

\section{The goal of $\mathrm{HHMI}$ funding has been, and remains, to support scientists with innovative ideas who may not receive support from government or industry becausetheir research is basic or 'blue sky' research}

telomere structure at the LMB. "It's not a new idea-the LM B is [over] 50 years oldbut I think it's a great step," she said. "There is a great need to integrate disciplines to tackle scientific problems. ... I believe it is much more efficient to have a few hundred scientists under one roof, centrally funded, taking risks, not having to apply for grants." In fact, the LM B's success has come largely from funding long-term work with risky outcomes, observed Nobel laureate John Sulston in his book The Common Thread (Bantam Press, London, 2002). In 1947, the MRC established a lab for 'research on the molecular structure of biological systems' to enable Max Perutz, the laboratory's first director, and John Kendrew to develop their research using X-ray diffraction to study proteins. "It took Max Perutz 23 years... to solve the structure of haemoglobin, and many chemists and biologists thought he was wasting his time," Sulston wrote. "You didn't-and still don't-have to justify everything in advance; you were just given the time, and a limited amount of space and resources, to get on with it." A similar spirit is found in other internationally successful research institutions, such as the EMBL or the German Max Planck Institutes. It is therefore an intriguing experiment: how will $\mathrm{HHMI}$, with its considerable funds, add to these successes with its own research institute?

A ccording to Rubin, $\mathrm{HHMI}$ does not seek to change its original mandate of supporting individual scientists, but rather to complement its model of funding about 320 researchers each year at their 70 home institutions. The goal of 